\title{
A Comparative Study to Evaluate a Simple Method for the Management of Postoperative Bleeding Following Palatoplasty
}

\author{
Percy Rossell-Perry ${ }^{1}$, William J Schneider ${ }^{2}$, Arquímedes M. Gavino-Gutierrez ${ }^{3}$ \\ ${ }^{1}$ Outreach Surgical Center, Program Lima Peru, ReSurge International, Lima, Peru; ${ }^{2}$ Fort Sanders Regional Medical Center, Knoxville, TN, \\ USA; ${ }^{3}$ A.B. PRISMA, Lima, Peru
}

Bleeding, is one of the most common postoperative complications after palatoplasty in patients with cleft palate. The purpose of this article is to present our experience using a Foley catheter balloon for perioperative palatoplasty bleeding management. A retrospective data analysis was performed for all cases of palatoplasty performed by the author from 1999 to 2012 that experienced postoperative hemorrhage. These patients were managed by utilizing posterior nasal compression with a Foley catheter balloon for the period 2006 to 2012. We have compared two methods (we use before 2006 the reoperative method) with regards to the later development of palatal fistulae and cases with reoperative hemostasis. The study found no statistically significant differences between the conventional and proposed method in relation to the development of palatal fistulae $(P=0.7)$. These findings suggest that nasal packing using a Foley balloon is a safe and effective method for postoperative bleeding control after palatoplasty in patients with cleft palate.

Keywords Cleft palate / Hemorrhage / Foley catheterization
Correspondence: Percy Rossell-Perry Outreach Surgical Center, Program Lima Peru, ReSurge International, 120 Schell St Apt 1503 Miraflores Lima 18, Peru

Tel: $+51-14452058$

Fax: +51-14452058

E-mail: prossellperry@gmail.com

The Outreach Surgical Center Program Lima Lima-Perú is supported by ReSurge International Foundation, USA.

No potential conflict of interest relevant to this article was reported.

Received: 29 Jan 2013 • Revised: 19 Apr 2013 - Accepted: 20 Apr 2013

pISSN: 2234-6163 • elSSN: 2234-6171 • http://dx.doi.org/10.5999/aps.2013.40.3.263 • Arch Plast Surg 2013;40:263-266

\section{INTRODUCTION}

Bleeding that requires reoperative hemostasis is one of the most common postoperative complications after palatoplasty in patients with cleft palate $[1,2]$. This complication mainly presents intraoperatively before extubation (when the patient is waking up) and sometimes when the patient is in the recovery room. The conventional method for arresting this postoperative hemorrhage includes the patient's return to the surgical room, reintubation, and reoperative hemostasis.

Under this scenario, reintubation is more difficult than the first intubation and patients who were reintubated have been reported to have a higher incidence of complications such as bleeding, laryngeal spasm, bronchospasm, endobronchial rupture, blood aspiration, and pneumonia [3-7]. Posterior nasal packing using a Foley balloon catheter has been described before in the management of epistaxis [8-10]. However, this method has not been previously reported in postoperative bleeding after palatoplasty.

The purpose of this article is to present our experience using a Foley catheter balloon for perioperative palatoplasty bleeding management in patients with a cleft palate. 


\section{IDEA}

Data collection from a retrospective chart review was completed for all of the palatoplasties performed by the corresponding author that experienced postoperative bleeding from 1999 to 2012.

From 1999 to 2005, we were using the conventional method (reintubation and reoperative hemostasis) for any significant postoperative hemorrhage and since 2006 we have used posterior nasal packing with a Foley catheter.

All these patients underwent surgery using two flap palatoplasty.

We compare these two methods in relation with the need for reoperative hemostasis and the development of palatal fistulas.

Once the hemorrhagic event is presented, using sterile gloves, the surgeon must clean the mouth, removing the clots. After this, using two fingers and gauze, gentle pressure is applied against the palate in order to control the bleeding. Then antibiotic nasal ointment is applied to the balloon catheter, and the device is advanced completely into the nostril (cleft side) and the catheter tip is visualized in the back of the throat.

The balloon is inflated with up to $10 \mathrm{~mL}$ of sterile water (the volume depends on the patient's age).

In the sample studied, the volume of the filled balloon necessary to stop the bleeding was not more than $10 \mathrm{~mL}$ and may have depended on the size of the oropharyngeal space. The balloon is displaced gently until it is seated posteriorly between the soft palate and oropharynx (Figs. 1,2). The surgeon must check the control of the bleeding after the balloon is filled and placed. Finally, (Xeroform wrap) is applied to prevent alar necrosis. In addition, adhesive tape is applied across the catheter against the forehead to keep the balloon from dislodging. Under our protocol the patient is extubated awake. This maneuver allowed

Fig. 1. Diagram of the sagittal section of the head

Location of the balloon between the soft palate and the oropharynx.

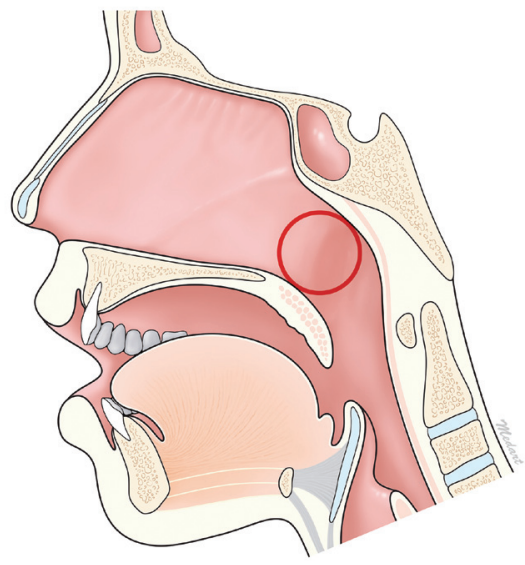

us to identify any bleeding related to the extubation procedure. Most of the cases presented here were related to incomplete intraoperative bleeding control. In our experience, patients tolerate the balloon and catheter very well. Any discomfort and pain are mild. The balloon is left in place for 12 to 24 hours, until the bleeding is controlled. Then the balloon is deflated first, using a syringe and if the bleeding does not return after 30 minutes the Foley catheter may be carefully removed. The size of the Foley catheter (diameter) is not relevant. The authors prefer a smaller one $(10 \mathrm{~F})$ in order to provide more comfort to the patient. Antibiotics may be prescribed. Agents that cover Staphylococcus species (e.g., cephalexin, amoxicillin) can prevent sinusitis and toxic shock syndrome. If the method fails the patient should be returned to the surgical room and proceed using the conventional method (reintubation and reoperative hemostasis) should be performed.

A two-sample test of proportions was performed to assess the statistical significance between the two methods. $\mathrm{P}<0.05$ yielded a confidence level of $95 \%$. The data were analyzed using Stata 11.0 software.

All patients with cleft palate underwent surgery by the corresponding author (P.R.) since 1999. Of those, 70 patients (5.54\%) had significant postoperative bleeding, which required specific management. We observed 38 patients with postoperative bleeding during this time. All of these were controlled using the conventional method (reintubation and reoperative hemostasis). We observed 32 patients with postoperative bleeding during this time. Almost all of these (except three) were controlled using posterior nasal packing with a balloon. There was a statistically significant difference between the two methods $(\mathrm{P}<0.05)$. The comparative study found no statistically significant differences between the conventional and proposed meth-

Fig. 2. Postoperative view of a cleft palate repair

The balloon is applied gentle against the palate to control the bleeding.

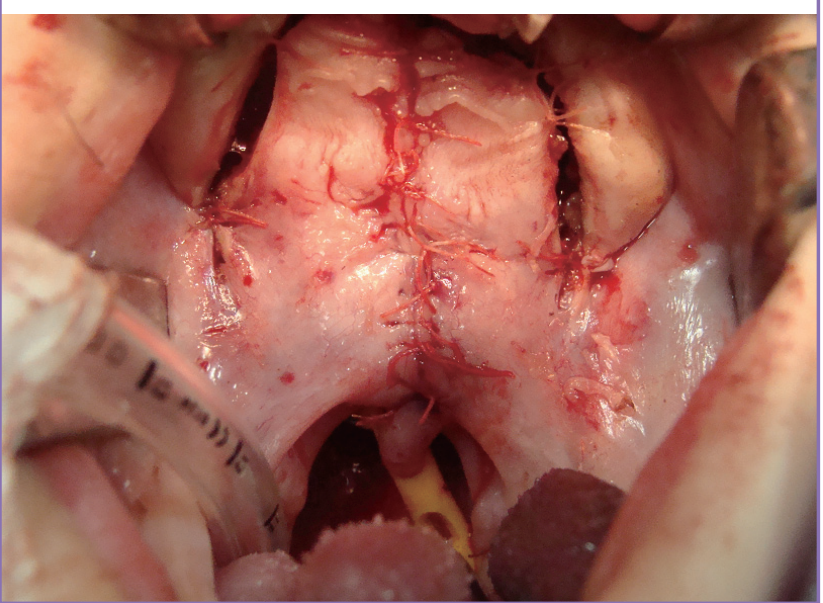


Table 1. Distribution of patients with cleft palate managed by the Outreach Surgical Center Program Lima 1999 to 2012

\begin{tabular}{|lcccc|}
\hline Palatoplasties & No. patients & Hemorrhage & Reoperative hemostasis & Fistulas \\
\hline $1999-2005$ & 622 & 38 & 38 & $622 / 32^{\text {a) }}(5.14 \%), 38 / 2^{\text {b) }}(5.26 \%)$ \\
$2006-2012$ & 640 & 32 & 2 & $640 / 30(4.68 \%), 32 / 1(3.12 \%)$ \\
\hline${ }^{a}$ Total number of patients; ${ }^{\text {b) }}$ Number of cases with hemorrhage. & &
\end{tabular}

Table 2. Comparison of the palatal fistula rate with each of the two methods for the management of postoperative bleeding following palatoplasty

\begin{tabular}{|lccc|}
\hline $\begin{array}{l}\text { Palatoplastices } \\
\text { No. }\end{array}$ & $\begin{array}{c}\text { Postoperative } \\
\text { fistulas }\end{array}$ & $\begin{array}{c}\text { 95\% confident } \\
\text { level }\end{array}$ & P-value $^{\text {a) }}$ \\
\hline $1999-2005(622)$ & $2 / 38$ & $5.3(-1.8,12.4)$ & 0.7 \\
\hline $2006-2013(640)$ & $1 / 32$ & $3.1(-2.9,9.2)$ & \\
\hline a)Two sample test of proportions. & & \\
\hline
\end{tabular}

od in relation to the development of palatal fistulae $(\mathrm{P}=0.7)$ (Tables 1,2). The mean age at the time of surgery was 23.44 months (range, 9 to 378 months). The mean age of the patients with bleeding was 46.2 months (range, 23 to 378 months).

\section{DISCUSSION}

Postoperative hemorrhage is a common and serious complication after palatoplasty in patients with cleft palate $[1,2]$.

There are no reports about the incidence of this complication, however in our experience this occurs more commonly in older patients (adults) and during the early postoperative period. Later presentation of bleeding (after 2 or 3 days) is rare. The Foley urinary catheter has been used in the management of posterior epistaxis for several decades, yet it has never been designed or licensed for this purpose [8-10].

Despite a lack of uniformity in balloon use, it is frequently successful in arresting nasal hemorrhage.

No previous reports of the use of the Foley catheter in postoperative bleeding management after cleft palate repair have been published.

As postoperative bleeding is a rare event, the number of cases has been considered to be a limitation of this study.

In this study, we evaluated the efficacy and safety of this method in postoperative bleeding after palatoplasty in patients with cleft palate.

Only 3 (7.89\%) of 38 patients required reoperative hemostasis $(\mathrm{P}<0.05)$.

The source of the bleeding in these patients was the greater palatine artery, which is not affected by the balloon compression.

The source of the bleeding in the patients treated using the catheter balloon was the vessels of the soft palate (nasal mucosa and muscular).

This method can control any bleeding coming from the nasal mucosa vascular plexus and small vessels of the soft palate but not from the anterior portion of the palate or the greater palatine vessels.

We have not seen recurrence of hemorrhage in patients treated using the balloon.

In 4 of 70 cases of postoperative bleeding, it started between the third and fifth postoperative day. Three of them were related to the greater palatine artery and one case was related to coagulopathy.

We have not seen any complication in relation to the use of the Foley catheter. This is because of the short term use (12 to 24 hours). Most of the previously reported complications, such as sinusitis and toxic shock syndrome, are associated with a longer period of use $[8,9]$.

Reflex bradydysrhythmia can develop because of stimulation of the deep posterior oropharynx by packing [10]. We have not observed this complication either.

In addition we did not observe any airway obstruction or persistent and significant gag reflex or harmful reaction to the wound related to the use of the balloon.

The fistula rate was similar in both groups in this study, so there is not an increased risk of palatal fistula relative to the compression of the balloon.

We repaired the cleft palate using $5 / 0$ absorbable sutures after extended dissection of the vascular pedicle of the flap to obtain a closure without any tension and low incidence of fistulas (4.91\% in our series).

This condition allow us to use the balloon without any increased risk of dehiscence or palatal fistula.

Finally, we may recommend intraoperative use (at the end of the surgery) of the Foley balloon to prevent and/or obtain control of bleeding.

This form of use is easier to apply (under intubation and direct vision) and less traumatic for the patient.

This technique is recommended as an effective and relatively simple and safe method to control postoperative hemorrhage following palatoplasty.

As we observed no increased rate of fistula between these groups we conclude that the use of the balloon does not create 
additional tension in the closure of the palate and thus there is not increased risk of development of palatal fistula or dehiscence.

\section{REFERENCES}

1. Fillies T, Homann C, Meyer U, et al. Perioperative complications in infant cleft repair. Head Face Med 2007;3:9.

2. Rossell-Perry P. Tratamiento de la fisura labio palatina [Internet]. Lima [PE]: Ciudad Universitaria; 2009 [cited 2013 May 4]. Available from: http://es.scribd.com/doc/ 81137002/Tratamiento-de-La-Fisura-Labio-Palatina.

3. Menon N, Joffe AM, Deem S, et al. Occurrence and complications of tracheal reintubation in critically ill adults. Respir Care 2012;57:1555-63.

4. Rashkin MC, Davis T. Acute complications of endotracheal intubation. Relationship to reintubation, route, urgency, and duration. Chest 1986;89:165-7.

5. Torres A, Gatell JM, Aznar E, et al. Re-intubation increases the risk of nosocomial pneumonia in patients needing mechanical ventilation. Am J Respir Crit Care Med 1995;152: 137-41.

6. The Spanish Lung Failure Collaborative Group. Prospective study of incidence, causes, and complications of patients requiring reintubation. Am J Respir Crit Care Med 1997;155: A404.

7. Desalu I, Adeyemo W, Akintimoye M, et al. Airway and respiratory complications in children undergoing cleft lip and palate repair. Ghana Med J 2010;44:16-20.

8. Holland NJ, Sandhu GS, Ghufoor K, et al. The Foley catheter in the management of epistaxis. Int J Clin Pract 2001;55: 14-5.

9. Hartley C, Axon PR. The Foley catheter in epistaxis management: a scientific appraisal. J Laryngol Otol 1994;108:399402.

10. McFerran DJ, Edmonds SE. The use of balloon catheters in the treatment of epistaxis. J Laryngol Otol 1993;107:197200. 